\title{
Hybrid Systems and Adaptive Foraging Multi-Agent Approaches Towards Strategic Marketing Decision-Making \\ Shuliang $\mathbf{L i}^{*}$ \\ Westminster Business School, University of Westminster, 35 Marylebone Road, London NW1 5LS, United Kingdom
}

\section{Editorial}

Increased competition, dynamic consumer behaviour, and changing economic and political environments all present challenges to marketing managers. With the revolution brought by ICT and new media, decision-makers need to ensure that they plan effectively and efficiently in order to survive and flourish. Making sound and timely marketing decisions and strategies has never been an easy task.

In view of Herbert Simon's bounded rationality of the human mind in solving complex problems, efforts have been devoted to identify managers' needs for computerised support for strategic marketing planning. In 1997 and 1998, we undertook a large scale questionnaire survey to explore managers' needs for computer-based support for marketing strategy formulation, existing provision of computerized support, and the gaps between the actual needs and the provision. The questionnaire sampling frame consisted of manufacturing companies geographically located in the UK. A total of 900 companies with more than 500 employees were randomly selected from the FAME (Financial Analysis Made Easy) CD-ROM databases. 104 responses were received after follow-ups. This was the first comprehensive study in the world to investigate relevant key issues. Our study extends the findings to the UK manufacturing companies and clarifies who needs computer-based support. The mail survey also reveals that, in many companies, two or more directors share the responsibility. The survey findings suggest that both analysis and intuition are important. It is also confirmed that coping with uncertainty and ambiguity is an issue. Managers' needs for computerised support in the digital age are clarified. This study extends the literature by focusing on using systems for marketing strategy development in UK manufacturing companies and investigates wider range of support systems and tools including databases, spreadsheets, marketing information systems, executive information systems, decision support systems, expert systems, and others. It was the first attempt to explore the level of managerial satisfaction with the systems used for marketing strategy development and the factors leading to dissatisfaction. The findings extend the literature by discovering such factors as limited support capabilities, inability to couple analysis with managerial judgement, inability in dealing with uncertainty, etc. It was also the first study to explore the factors holding companies back from using computer-based support for marketing strategy development by identifying such factors as lack of appropriate systems, lack of required data and information to run relevant systems, lack of knowledge and skills in systems, etc. The findings from this study provide a solid foundation for designing, developing and applying computer-based support systems for the process of strategic marketing planning.

Following the above-mentioned survey findings, we proposed a new conceptual framework for the creation and use of hybrid intelligent systems in support of marketing strategy formulation through linking the step-by-step marketing planning process, analytical models, various decision support and artificial intelligence techniques, and human judgement and intuition into one integrated framework and paradigm.

We then created, tested and evaluated relevant novel approaches and associated research software prototypes for hybrid intelligent systems that integrate the powers of different support techniques and technologies, such as expert systems, fuzzy logic, artificial neural networks, group Delphi to support the formulation of marketing strategies where the required conditions are not satisfactorily met by individual techniques and technologies. Typically, our MarStra system was developed to combine the strengths of diverse support techniques. The system was validated and evaluated with marketing directors and senior managers in five large British companies. We then went on to construct a hybrid system, entitled as GloStra, for assisting with global marketing strategy development, and HyStra for hybridising the analytic hierarchy process, computer simulation and fuzzy expert systems for strategy formulation under uncertainty, with associated new conceptual frameworks established. These studies provide new insights and methods for hybrid intelligent decision support system development and applications.

Aiming to deliver marketing strategy expertise and guidelines on the web, transport the decision support models and tools over the Internet or intranets, provide intelligent support round the clock and around the world, link the formulation of marketing strategies with the development of e-commerce strategies, and connect web-based intelligent support with group judgment and vision, we developed a new research software prototype, called WebStra, and proposed a fresh three-step approach to aid the key stages of strategic marketing planning by hybridising web-enabled a fuzzy expert system, group Delphi and managerial inputs and intuition. Collaborating with Jim Zheng $\mathrm{Li}$, we also proposed and developed the novel web-enabled architecture, models and a web-based hybrid system, called WebInternational, combining knowledge automation, fuzzy logic and online databases for international marketing planning. We have also designed a webbased hybrid simulation, fuzzy logic and knowledge automation system, entitled as WebDigital, for digital marketing planning and digital marketing strategy-making. In addition, we have produced the WebIntegrated hybrid system for formulating integrated conventional, digital, mobile and social media marketing strategies. Furthermore, we have created web-based hybrid system, entitled as WebMarP for the assessment of conventional marketing and social media marketing performance. Relevant new approaches and systems were validated and evaluated by marketing managers and directors as efficient and effective in terms of helping overcome the time zone problem; helping overcome the geographical location barrier; improving the speed of decision-making; helping understand the factors influencing decision-

*Corresponding author: Shuliang Li, Westminster Business School, University of Westminster, 35 Marylebone Road, London NW1 5LS, United Kingdom, E-mail: lish@wmin.ac.uk

Received April 16, 2012; Accepted April 16, 2012; Published April 17, 2012

Citation: Li S (2012) Hybrid Systems and Adaptive Foraging Multi-Agent Approaches Towards Strategic Marketing Decision-Making. JAccount Mark 1:e104. doi: $10.4172 / 2168-9601.1000$ e104

Copyright: ( 2012 Li S. This is an open-access article distributed under the terms of the Creative Commons Attribution License, which permits unrestricted use distribution, and reproduction in any medium, provided the original author and source are credited. 
making; aiding decision-making by delivering web-based planning knowledge, analytical models and guidelines; helping couple webenabled knowledge automation with human judgment and creativity; helping deal with uncertainty; helping generate relevant alternatives or options in the process of planning; helping improve the quality of planning; and enhancing confidence and satisfaction about the system and its output or advice.

In collaboration with Jim Zheng Li, we have also conducted original research work on mathematical description, computational modelling, knowledge automation, symbolic representation frameworks and software examples for international marketing decision-making and digital marketing planning. In addition, we have made pioneering attempts on proposing and setting up a novel conceptual framework, process and method, and creating and evaluating new multi-agent hybrid system research prototypes, AgentsInternational, integrating multiple intelligent software agents, computer simulation, fuzzy logic and expert systems for setting marketing strategies and competitive strategies, and supporting international marketing decision-making under uncertainty. Empirical evaluation studies with marketing directors and managers have tested the overall value (e.g. effectiveness and efficiency) of our novel paradigm, architecture, methods and multiagent systems. These studies have provided new understanding for the design, creation and use of hybrid intelligent multi-agent approaches, models and systems in business and management decision-making, and particularly, in strategic marketing planning in global contexts.
We are currently undertaking original research on hybrid self-organising, self-surviving and adaptive foraging multi-agent approaches and systems towards developing and optimising integrated strategies for marketing and competing in global settings. This research project suggests new research opportunities and opens up at least the following new areas: Theories, frameworks and models for ICT-enabled interactive conventional, digital, mobile and social media marketing strategy formulation and optimisation in global settings and China in particular; frameworks, approaches and Internet-enabled hybrid intelligent systems for linking web analytics, distributed marketing intelligence in global contexts; Internet-enabled context-sensitive approaches and frameworks for monitoring, tracking and reacting to dynamic competitive moves and customer demands; integration of deductive, inductive and abductive reasoning methods for strategic marketing planning and strategy formulation in dynamically changing business environments; paradigms, architecture, approaches and software tools for the development and use of Internet-enabled multiple software agents in support of integrated marketing planning in global settings; the development, validation, evaluation and implementation of relevant models, frameworks and novel decision support systems for international marketing decision-making; and the development and use of social insect behaviour mimicking, smart self-organising and self-surviving multi-agent models, adaptive foraging frameworks and relevant software tools for automating, developing and optimising international marketing decisions. 